\title{
Extraction, Isolation and Identification of Antimicrobial Substances from Bacillus amyloliquefaciens CMN1308
}

\author{
Yingyou FANG ${ }^{1 \mathrm{a}}$, Linling $\mathrm{LI}^{1 \mathrm{~b}}$, Yongliang ZHENG ${ }^{1,2}$, Honghui YUAN ${ }^{1,2}$, \\ Xuehua $\mathrm{ZHANG}^{1}$, Shuiyuan $\mathrm{CHENG}^{1,2}$, Hua $\mathrm{CHENG}^{1 *}$ \\ ${ }^{1}$ Huanggang Normal University, Economic Forest Germplasm Improvement and Comprehensive Utilization of Resources \\ of Hubei KeyLaboratory, Huanggang, 438000,China; 2042834129@qq.com; lilinling1437@126.com; 11169214@qq.com; \\ 448503382@qq.com; 455262713@qq.com;s_y_cheng@sina.com; chenghua1437@126.com (*orrespondingauthor) \\ ${ }^{2}$ Wuban Polytechnic University, College of Biology and Pharmaceutical Engineering, Wuban, 430023, China \\ ${ }^{a b}$ These authors contributed equally to the study
}

\begin{abstract}
Four separation methods of antimicrobial substances produced by CMN1308 (Bacillus amyloliquefaciens) were evaluated and selected according to number of antimicrobial substances and its activity in vitro. The results showed that extraction by acid precipitation of the fermentation supernatant of CMN1308 was the best with a diameter of inhibition zone of pathogen fungi P. expansum of $12.3 \mathrm{~mm}$ in a laboratory bioassay. Applying a silica thin layer chromatography (TLC), SDS-PAGE and other separation technologies we isolate antimicrobial substances, and the separated band were cut off for mass spectrometry analysis. The TLC of crude extract of CMN1308 show a topical band corresponding with the surfactin standard ( $\mathrm{Rf}$ value $=0.75$ ), proved that the strain CMN1308 can produce this surface active compound. The mycoprotein extracted from CMN1308 was separated by Tricine-SDS-PAGE modified with the addition of urea in the separation gel. After mass spectrometric analysis and protein characterization, the isolated mycoprotein showed a maximum ion peak at $\mathrm{M} / \mathrm{Z}$ of 2679 and molecular weight of $29.5 \mathrm{kDa}$, matching with protein flagellin. The extracellular antimicrobial protein of strain CMN1308 display four bands after urea-Tricine-SDS-PAGE, but after mass spectrometry analysis only two bands were identified. Band "A" with a maximum ion peak at M/Z of 1926 and molecular weight of $49.8 \mathrm{kDa}$, aligned with NCBI database, matching with DLDH (dihydrolipoamide dehydrogenase enzyme). Band "D" show the maximum ion peak at M/Z of 2936 and molecular weight of $22.4 \mathrm{kD}$, matching with a chitin binding protein. Thus, the strain CMN1308 has the potential to be developed as a commercial biological control agent for chestnut common pathogenic fungi.
\end{abstract}

Keywords: antimicrobial activity, Castanea mollissima, inhibition zone, lipopeptides, mass spectrometry, TLC

\section{Introduction}

Biological control has the potential to play an important role in managing plant diseases and pathogenic microorganisms in food. Bacillus amyloliquefaciens has developed a secretion system that allows it produce a variety of secondary metabolites with antagonistic activity (Scholz et al., 2014), mainly divided into antimicrobial protein type and antimicrobial peptides, they can inhibit germination of fungi growth of bacteria and possess other biological control effects, so it is widely used in biological control of plant diseases (Elmer et al., 2008). Antimicrobial peptides are widespread produced among $B$. amyloliquefaciens, different Bacillus strains are producers of antimicrobial substances with potential applications as biocontrol agents (Benitez and Velho, 2012). Various antimicrobial substances produced by Bacillus have been identified, such as fengycins, iturins, and surfactines, which belong to nonribosomally peptides (Stein, 2005).
The chestnut fruit is considered of high nutritional value and it also a long history of usage as traditional food in Chinese. However, browning and postharvest diseases are serious technical trouble in chestnut processing (Zhou et al., 2015a). This problem cause enormous economic loss in Asia Based on the previous work, the strain CMN1308 was isolated from Chinese species of chestnut 'Meighong' by the research group and identified as B. amyloliquefaciens. CMN1308 showed a strong inhibition to the growth of pathogenic bacterium after picking. CMN1308 produces antimicrobial peptides that show broad antimicrobial spectrum and the antagonistic effect of this strain against phytopathogenic fungi was also demonstrated before (Zhang et al., 2016).

Actually, the more used purification methods are: salting out method, low temperature organic solvent precipitation, acid precipitation, ion exchange chromatography, gel molecular sieve chromatography, isoelectric precipitation, affinity chro- 
matography, adsorption column chromatography, ultracentrifugation, electrophoresis and reversed-phase liquid chromatography (Liao et al., 2014). The extraction, purification and identification of antimicrobial substances is an important part in biological control agents research (Moe et al., 2015). In order to isolation and identification of antimicrobial peptides of strain CMN1308, we used four different methods for separation and extraction of antimicrobial substances, from which we selected the extraction method to obtain a large amount of antimicrobial substances, and later its antimicrobial activity was evaluated using chromatography and other separation techniques. The objectives of this research were to evaluate the antimicrobial activity of CMN1308 and its antimicrobial peptides in the biological characteristics and the potential application of this strain for disease control, especially for chestnut common decompose management.

\section{Materials and Methods}

\section{Bacterial strains and culture conditions}

Antagonist: B. amyloliquefaciens subsp. CMN1308, isolated from the inside of chestnut 'Meiguihong' and identified by morphological, physiological experiments and ITS gene analysis by Hua (Juan, 2014). For the production of antimicrobial peptides, CMN1308 was grown in $100 \mathrm{ml} \mathrm{LB}$ medium at $37^{\circ} \mathrm{C}$ in a rotary shaker at $120 \mathrm{rpm}$ for $24 \mathrm{~h}$.

Pathogenic fungi: Penicillium expansum and Stachybotrys chartarum, isolated from the chestnut described by Zhang (Zhang et al., 2016) and preserved with $10 \%$ DMSO in $-70^{\circ} \mathrm{C}$ refrigerator by the economic forest germplasm improvement and comprehensive utilization of resources of Hubei key laboratory. Pathogenic fungi were kept on the PDA culture at $25^{\circ} \mathrm{C}$ at 120 rpm for $48 \mathrm{~h}$.

\section{Extraction and antimicrobial activity of mycoprotein of strain CMN1308}

The mycoprotein of CMN1308 was extracted using a bacterial protein micro extraction kit (TIANDZ, China). According to the manual, take $2 \mathrm{~mL}$ overnight bacteria fermentation broth, centrifuge for $1 \mathrm{~min}$ at $12000 \mathrm{rpm}$, discard supernatant. Each one of the $10 \mathrm{mg}$ wet weight biomass was precipitated with $0.5 \mathrm{~mL}$ solution $\mathrm{A}$ and $50 \mu \mathrm{L}$ solution $\mathrm{B}$, and mix. Put it on ice for $30 \mathrm{~min}$ to 1 hour to let bacteria liquid become clear. Centrifuge at $4^{\circ} \mathrm{C}$ for $1 \mathrm{~min}$ and $12000 \mathrm{rpm}$, the supernatant was transferred to a $1.5 \mathrm{~mL}$ centrifuge tube and the protein solution obtained can be placed in a $-70^{\circ} \mathrm{C}$ refrigerator until use (Trefilov $e t$ al., 2015). The antimicrobial activity of the mycoprotein against $S$. chartarum and $P$. expansum was determined by the Oxford cup method described by Yang (2011). $100 \mu \mathrm{L}$ spore suspensions of various pathogenic were deposited across the plate with a sterile cell spreader on PDA agar plates. $20 \mu \mathrm{L}$ of $10^{7} \mathrm{CFU} \mathrm{ml}{ }^{-1} \mathrm{CMN} 1308$, cultured for $24 \mathrm{~h}$ in plate, was placed as a drop on a sterile oxford cup, which was placed on the agar medium with several cups per plate, at $2 \mathrm{~cm}$ distance from each other.

\section{Extraction of extracellular antimicrobial substances from strain CMN1308}

In this study, the extracellular antimicrobial substances of $B$. amyloliquefaciens were extracted by the hydrochloric acid precipitation method (Ye et al., 2011). CMN1308 sterile filtrate was placed into sterile triangular bottle, adding $7 \mathrm{~mol} / \mathrm{L}$ of concentrated hydrochloric acid to adjust $\mathrm{pH}$ to 2.0 and $4{ }^{\circ} \mathrm{C}$ overnight aging. Centrifugal repackaging at $50 \mathrm{~mL}$ tubes, each tube is $30 \mathrm{~mL}, 12000 \mathrm{r} / \mathrm{min}, 4^{\circ} \mathrm{C}$ centrifuge $20 \mathrm{~min}$, supernatant was discarded and $1.5 \mathrm{~mL}$ methanol $(\mathrm{pH}=7)$ was added to each tube, $4^{\circ} \mathrm{C}$ extract $8 \mathrm{~h}$. Then $10000 \mathrm{r} / \mathrm{min}, 4^{\circ} \mathrm{C}$ centrifuge 20 min, removal of precipitation, the supernatant is the crude extract. The liquid was transferred to a $1.5 \mathrm{~mL}$ centrifuge tube and stored in a $-20^{\circ} \mathrm{C}$ refrigerator. The antimicrobial activity of crude extract was determined by filter paper method (Wei and Liang, 2011).

\section{Silica gel TLC/ Sephadex G-75 column chromatography}

In order to isolate the antimicrobial substance of the strain CMN1308 and to identify whether it can produce surfactin. In this study, the TLC (thin layer chromatography chromatography) of the crude extracts and surfactin samples was carried out.

In GF254 TLC board $\left(20 \mathrm{~cm}^{*} 10 \mathrm{~cm}\right)$ at $2 \mathrm{~cm}$ of the bottom gently draw a horizontal line (Villeneuve et al., 1970). Point $5 \sim 10 \mu \mathrm{L}$ sample (the lipopeptid antimicrobial material and Surfactin standard sample) on the silica gel plate, in the different ratio of chromatography reagents (chloroform: methanol: water $=65: 25: 4)$ to expand $4 \mathrm{~h}$. When the solvent arrives at the front of the chromatography board, it is taken out and dried, and the separation results were observed under the ultraviolet light of the wavelength of $254 \mathrm{~nm}$ and analyzed using a gel imaging system (Pagoria et al., 2014).

The sample to be separated is extracellular antimicrobial crude extract. Sephadex G-75 column chromatography was used in this work ( $\mathrm{Li}$ et al., 2013). With $0.02 \mathrm{~mol} / \mathrm{L} \mathrm{pH} 6.8$ phosphate buffer as the elution agent (mobile phase), flow rate is $0.5 \mathrm{ml} / \mathrm{min}$, collect 18 fraction volume is $3.0 \mathrm{ml}$. After chromatography, the separation fractions were detected by the Protein nucleic acid detector.

\section{Tricine-SDS-PAGE analyses}

To determine the molecular size of antimicrobial substance in CMN1308, the peptides were separated by Tricine-SDSPAGE as described by Jiang (2007). The polyacrylamide concentration on the separating gel was $16.5 \%(\mathrm{w} / \mathrm{v})$, and add 5.4 g urea every $15 \mathrm{ml}$ gel. The spacer gel concentration was $10 \%$. Electrophoresis was set at a constant voltage of $50 \mathrm{~V}$ for $1 \mathrm{~h}, 75 \mathrm{~V}$ for $2 \mathrm{~h}$ and finally $150 \mathrm{~V}$ for $1 \mathrm{~h}$. A standard rainbow molecular marker was used, with sizes ranging from 3 to $100 \mathrm{kDa}$. The gel was fixed with an isopropanol (20\%, v/v)-acetic acid $(10 \%, \mathrm{v} / \mathrm{v})$ solution, exhaustively washed with distilled water, and stained with coomassie brilliant blue for $45 \mathrm{~min}$, and then discolored twice with acetic acid for 2-3 h. The method can improve the separation effect of small molecular polypeptide, and has high resolution, and can effectively isolate $1-100 \mathrm{kDa}$ peptide and protein (Hermann, 2006).

\section{Mass spectrometry analysis}

After Coomassie brilliant blue staining, the electrophoretic bands were cut to the $1.5 \mathrm{~mL}$ centrifuge tube sent to the biotechnology company by mass spectrometry. Tricine-SDSPAGE bands were used for decolorization, enzyme digestion, peptide concentration and removal of salt, then two-dimensional mass spectrometry analysis was carried out. 
310

Mass spectrometry analysis was carried out using the German Bruker Dalton Ultraflex III TOF/TOF mass spectrometer. The UV wavelength is $355 \mathrm{~nm}$, the acceleration voltage is $20000 \mathrm{~V}$, the repetition rate is $200 \mathrm{HZ}$, the best quality resolution is $1500 \mathrm{Da}$. The scanning quality range is $700-3200$ $\mathrm{Da}$, and the signal is collected. The mass spectra of all the experimental samples were obtained by default mode.

Protein identified: Using software flex Analysis (Bruker Dalton) to filter the baseline peak and identify the signal peak. Use BioTools software to search the NCBI database to find the matching of related proteins. Meanwhile, query its function to clear and definite what kind of protein it is.

\section{Results}

\section{Antimicrobial activity of CMN1308 bacterial protein}

To study the antimicrobial activity of CMN1308, bacterial protein micro-extraction kit (TIANDZ) was used to obtain the crude extract of bacterial protein in this study. In addition, the antimicrobial effect of bacterial protein measured by oxford cup method on $S$. chartarum is as shown in Fig. 1A. Compared with the control group, the bacterial protein of CMN1308 strain show obvious activity on pathogenic fungi, which illustrates that the crude extract of CMN1308 strain bacterial protein has some antimicrobial protein, and as to the variety of this antimicrobial substance, it requires for further TricineSDS-PAGE and mass spectrometry.

Antimicrobial activity of CMN1308's extracellular antimicrobial crude extract

From the results, the best extraction method was acid precipitation method. It was the best inhibitory effect with this method to extract the antimicrobial substance of CMN1308 fermentative supernatant on $P$. expansum of C. mollissima, and the mean diameter of inhibition zone was $12.3 \mathrm{~mm}$ (Fig. 1), Extracellular antimicrobial crude extract showed strong antimicrobial activity, which obviously inhibit the growth of $P$. expansum.

\section{TLC analysis of CMN1308 antimicrobial substance}

It can be estimated from Fig. 2 that the $R_{f}$ values of $A, B$ and $\mathrm{C}$ are in the range of $0.15-0.85$, but the developing solvent of chloroform, methyl alcohol and water in the proportion of 65: 25: 4 divided the crude extract into several distinct bands, and the chromatographic separation effect was the best. Thus, it was concluded that the optimum proportion of developing agent of chloroform, methyl alcohol and water is 65: $25: 4$.

After TLC was performed to the antimicrobial crude extract of CMN1308 in different proportions, the result after detection by gel-imaging system under ultraviolet was shown in Fig. 2. The result showed that the antimicrobia substance of CMN1308 was constituted by various molecules. As shown in Fig. 2, it can be clearly observed that the antimicrobia substance of CMN1308 was divided into several bands by TLC, and one special band was accordant with the $R_{f}$ value of surfactin standard product, by which it was confirmed preliminarily that CMN1308 strain could produce surfactin as the base ingredients containing antimicrobial substance of micromolecular peptides.

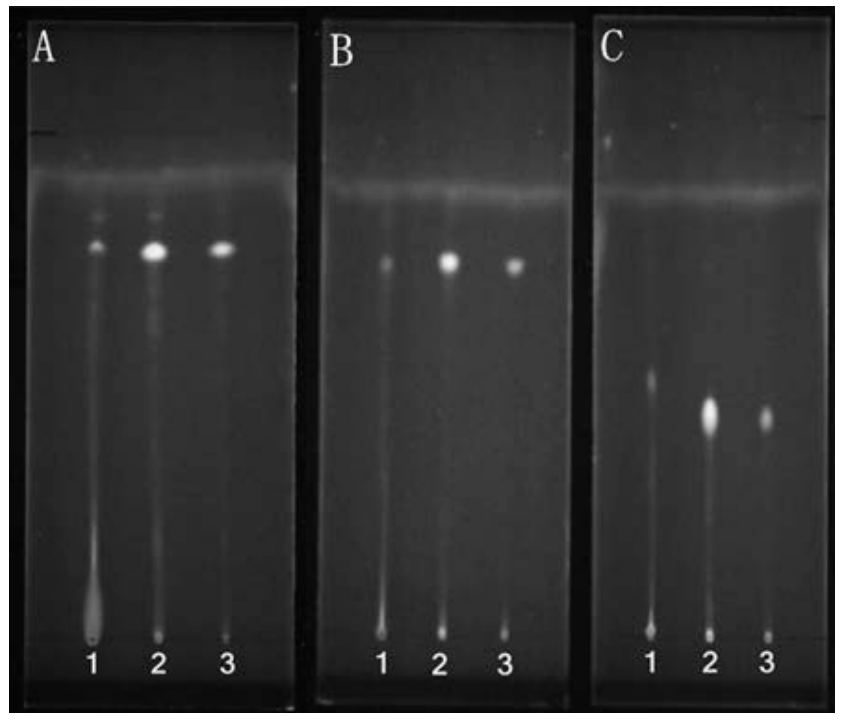

Fig. 2. TLC chromatograms of the antimicrobial substance from B. amyloliquefaciens CMN1308; A: chloroform: methanol: water $=65: 25: 4$ B: chloroform: methanol $=2: 1 \mathrm{C}$ : chloroform: methanol =5: 1 1-2: The antimicrobial substance from CMN1308; 3: Surfactin standard sample

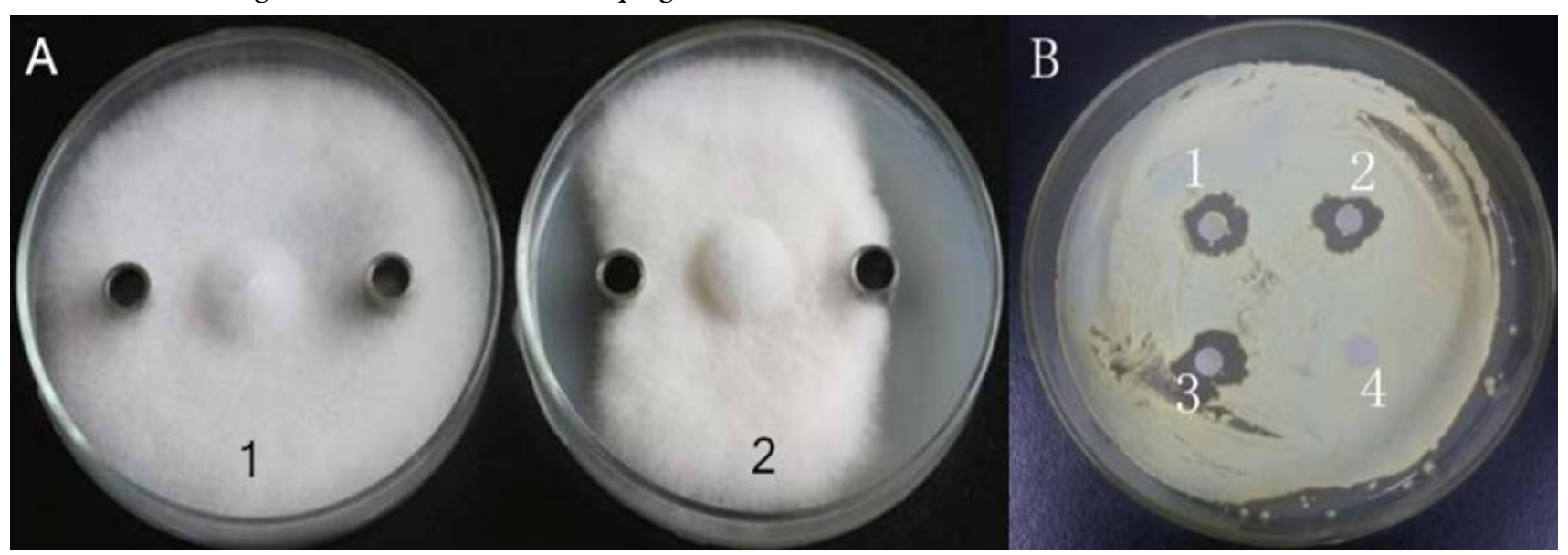

Fig. 1. The antimicrobial activity of B. amyloliquefaciens CMN1308's crude extract; A: the antimicrobial effect of bacterial protein on Stachybotrys chartarum 1: control (water), 2: the strain CMN1308 bacterial protein sample B: the antimicrobial activity of crude extract on Penicillium expansum 1-3: the crude extract of strain CMN1308, 4: control (methanol) 
Column chromatography of CMN1308 antimicrobial substance

After acid precipitation, the fermentative supernatant was collected, and methyl alcohol was used to extract the supernatant concentrate through Sephadex G-75 gel chromatography, and two chromatographic peaks could be obtained as shown in Fig. 3A. The result of antimicrobial activity test showed that eluent had no antimicrobial activity at peak 1, but distinct antimicrobial effect at peak 2 (Fig. 3B). After Tricine-SDS-polyacrylamide gel electrophoresis test, the antimicrobial substance was separated effectively. Thus, the eluent at peak 2 was merged and collected, dialyzed and concentrated for low temperature preservation.

\section{Tricine-SDS-PAGE electrophoresis}

The intracellular antimicrobial substance from CMN1308 were collected, which performed Tricine-SDS-PAGE electrophoresis (Fig. 4). According to the results, Two distinct bands were separated by the bacterial protein, of which the molecular weights were around $75 \mathrm{kD}$ and $29 \mathrm{kD}$. The second band was selected and cut off from the page, and mass spectrometry was performed.

To improve the resolution of polyacrylamide gel electrophoresis, $6 \mathrm{~mol} / \mathrm{L}$ urea was added into separation gel. The result of crude extract (extracellular antimicrobial substance of CMN1308) and 2 Markers performing TricineSDS-PAGE electrophoresis is shown as Fig. 4 . All the 8 bands of protein Marker (3.4-100 kDa) ran out distinctly.

The extracellular protein of CMN1308 performed SDSPAGE and showed as in Fig. 5. The crude extract of extracellular protein showed 4 bands with trailing, but not affecting cutting gel. The 4 bands were numbered from the top to down as A, B, C and D (molecular weight from $80 \mathrm{kD}$ to 20 $\mathrm{kD}$ separately), where the recovery gel was cut off and added into $1.5 \mathrm{~mL}$ tube for storage and performing mass spectrometry.

\section{Mass spectrometry of antimicrobial substance}

The Fig. 6 show the mass spectrometry data of intracellular antimicrobial substance band 1 . It can be seen from the results that the antimicrobial substance was interrupted into different ion fragments of charge-mass ratio. The intracellular protein molecular weight that was $29.5 \mathrm{kD}$ with the highest matching number with the result of Tricine-SDS-PAGE. Blasting with BioTools (Bruker Dalton), and it was analyzed that this bacterial protein was flagellin.
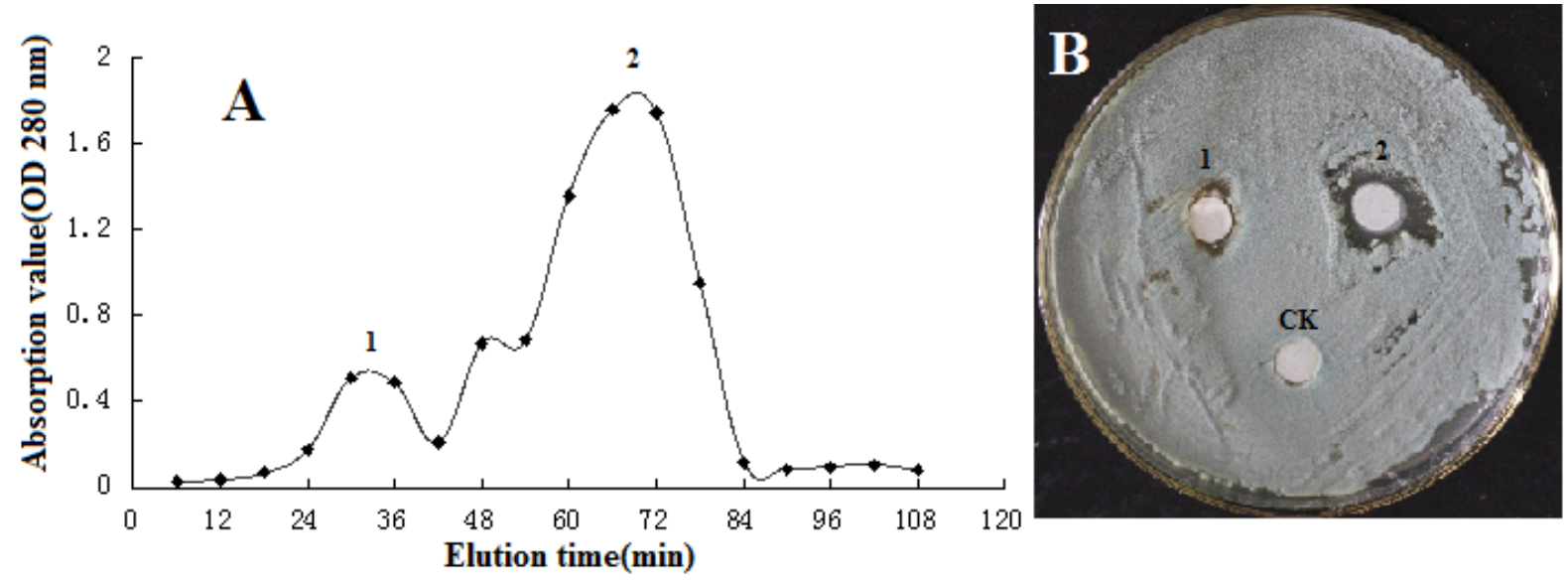

Fig. 3. Chromatogram of Sephadex G-75 analysis of antimicrobial substance A: Elution peak of antimicrobial substance; B: the antimicrobial effects of elution substance on $P$. expansum; 1 : chromatographic peak 1; 2: chromatographic peak 2

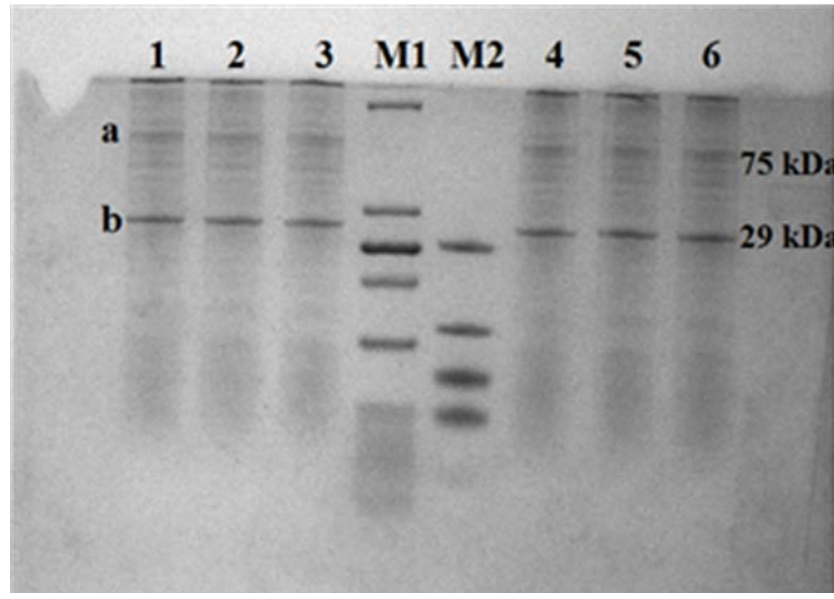

Fig. 4. Tricine- SDS-PAGE detection of mycoprotein from CMN1308; 1-6: the strain CMN1308 bacterial protein sample M1: Protein Marker; M2: Lipopeptide Marker ; a: band 1 ; b: band 2

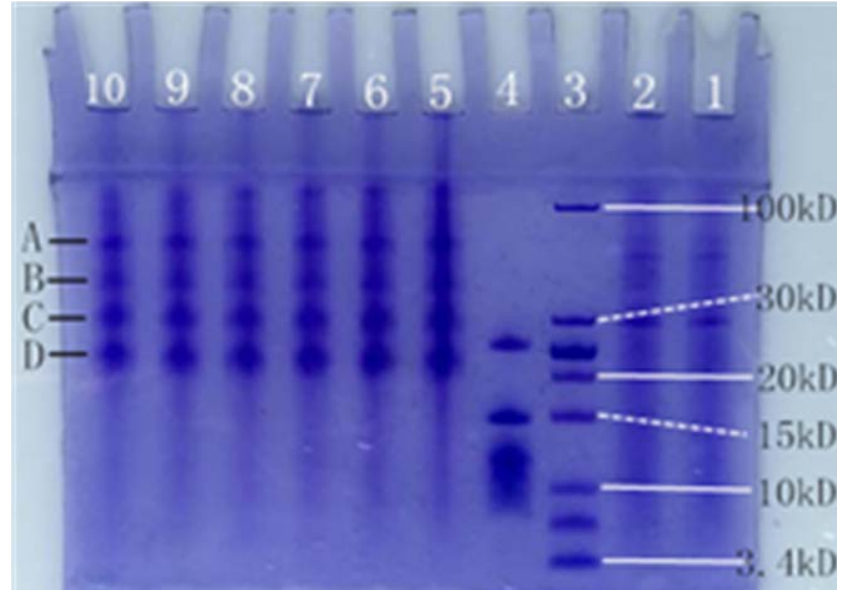

Fig. 5. Urea- Tricine- SDS-PAGE detection of antimicrobial substance; 1-2: Mycoprotein ; 3: Protein Marker; 4: Lipopeptide Marker; 5-10: Extracellular antimicrobial material 


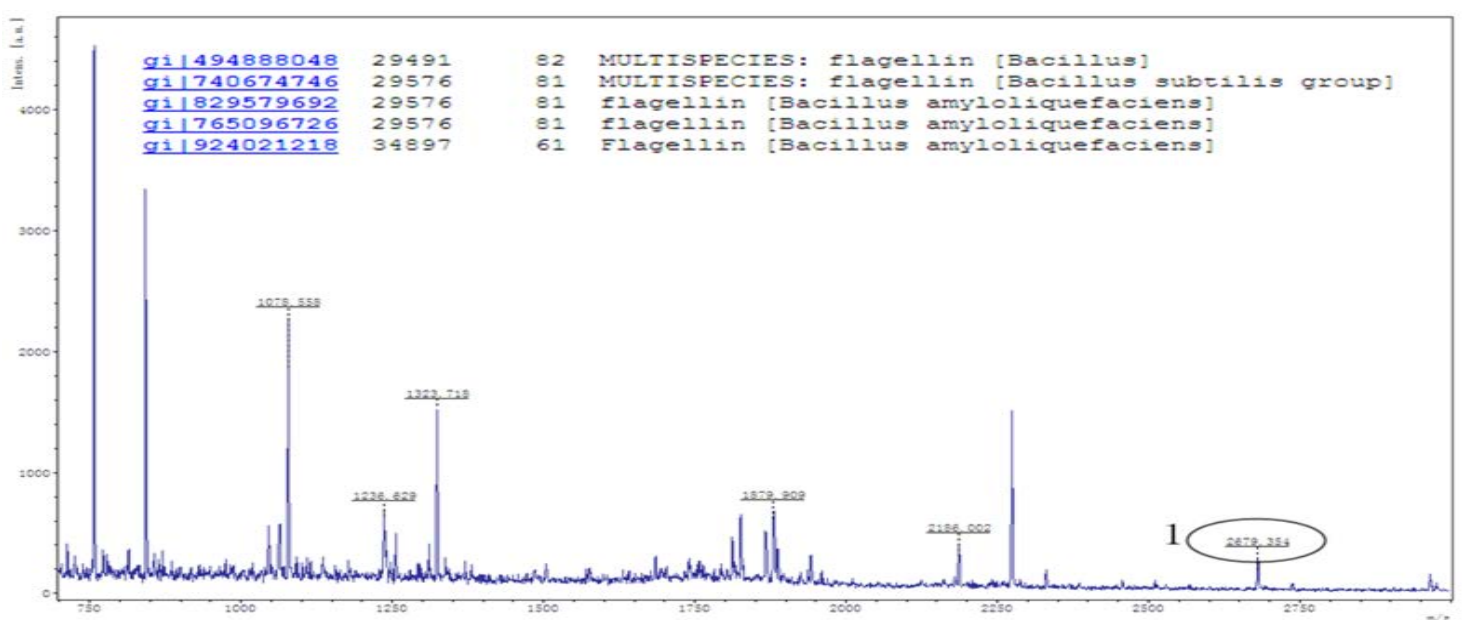

Fig. 6. The mass spectrum of mycoprotein from B. amyloliquefaciens CMN1308 Band b: 1- the maximum ion peak mass-tocharge ratio: 2679 ; the related protein molecular weight: $29.5 \mathrm{kD}$, the highest matching number: 82

Fig. 7 is the second-class mass spectrum of antimicrobial protein of CMN1308 in fermentative supernatant. It can be seen from picture that the maximum mass-to-charge ratio of ion peak was 1926 at this band. The software of flex analysis was used to filter baseline peak and identify signal peak. Afterwards, BioTools software was used to search NCBI database. The related protein molecular weight that was 49.8 $\mathrm{kDa}$ with the highest matching number (134) was found out (basically according with the result of Tricine-SDS-PAGE electrophoresis). The alignment results present that the substance at this band was DLDH. It can be seen from Fig. 7B that the maximum mass-to-charge ratio of ion peak was 2881 at this band. Align with NCBI database, it was found that most of the related protein was hypothetical protein, and the matching number was less than 30 .

The maximum mass-to-charge ratio of ion peak of Fig. $7 \mathrm{C}$ was 2928 at this band. Compared with NCBI database, most of the related protein was phage portal protein or hypothetical protein. The matching number was 31 , and the molecular weight was also $7492 \mathrm{Da}$, which was not accordant with the result of SDS-PAGE electrophoresis.

It can be seen from Fig. 7D that the maximum mass-tocharge ratio of ion peak was 2936 at this band. BioTools software was used to search NCBI database, the highest matching protein (70) was found out, the molecular weight of related protein was $22.4 \mathrm{kDa}$ which was accordant with the result of Tricine-SDS-PAGE electrophoresis. Searched on $\mathrm{NCBI}$, the substance at this band was chitin-binding protein.

\section{Discussion}

\section{Purification of antibacterial substances of strain CMN1308}

The crude extract obtained by acid precipitation method might indicate the presence of surfactant. To reach the best separation effect, the developing solvent of chloroform, methyl alcohol and water in 65: 25: 4 ratio was used for extracting the lipopeptides from thin layer chromatography on a silica gel was performed, and the $R_{f}$ value of a protein band was obtained according to the surfactin standard (Leelasuphakul et al., 2008). This further confirmed that the antibacterial substance contained micromocular lipopeptides, proving that CMN1308 strain could produce surfactin preliminarily.
Methyl alcohol was used to extract the supernatant, and Sephadex G-75 gel chromatography was performed after adjusting the concentration, where two chromatographic peaks were obtained.

The result demonstrated that peak 2 had more significant antibacterial effect. After performing polyacryl-amide gel electrophoresis, the antibacterial substance showed no distinct band. This may be because that (a) the concentration of antibacterial crude extract was too low after glucan column chromatography elution, and the active ingredients might be damaged during the process of concentration; (b) the resolution ratio of SDS-polyacrylamide was not enough to distinguish the antibacterial substance.

\section{Mass spectrometry of CMN1308 bacterial protein}

Two bands of the bacterial protein CMN1308 were obtained with acrylamide gel electrophoresis, and the results showed a deeper band cut off value to perform mass spectrometry. The band of this bacterial protein was broken into ion scraps by different mass-to-charge ratio by electrons, and the maximum mass-to-charge ratio of ion peak was 2679 . The software of flexAnalysis was used to filter the baseline peak and identify the signal peak. After which, the BioTools software was used for searching. The related protein molecular weight of $29.5 \mathrm{kDa}$ with that of the highest matching number (82) was found out, which was in accordance with the result of Tricine-SDS-PAGE electrophoresis. Meanwhile, the functions were analyzed, which showed that the substance at this band was flagellin [Bacillus amyloliquefaciens].

Flagellin is a granular protein that consists of bacterial flagellum fibre. This protein largely exists in almost all the bacteria that have flagellum (Miao et al., 2007), and the molecular weight varies depending on the bacterial species. The molecular weight of flagellin varies from $50 \mathrm{kDa}$ to $60 \mathrm{kDa}$ in the intestinal bacterial colonies, but the molecular weight of Bacillus spp. is around $30 \mathrm{kDa}$. The result of this study is in accordance with the results reported. According to the previous studies, several effective candidate vaccines were obtained through the mixture or fusion expression between bacterial flagellar proteins and exogenous antigens. Bacterial flagellum is the most potential adjuvant in candidate vaccines (Gómez Casado, 2015). 

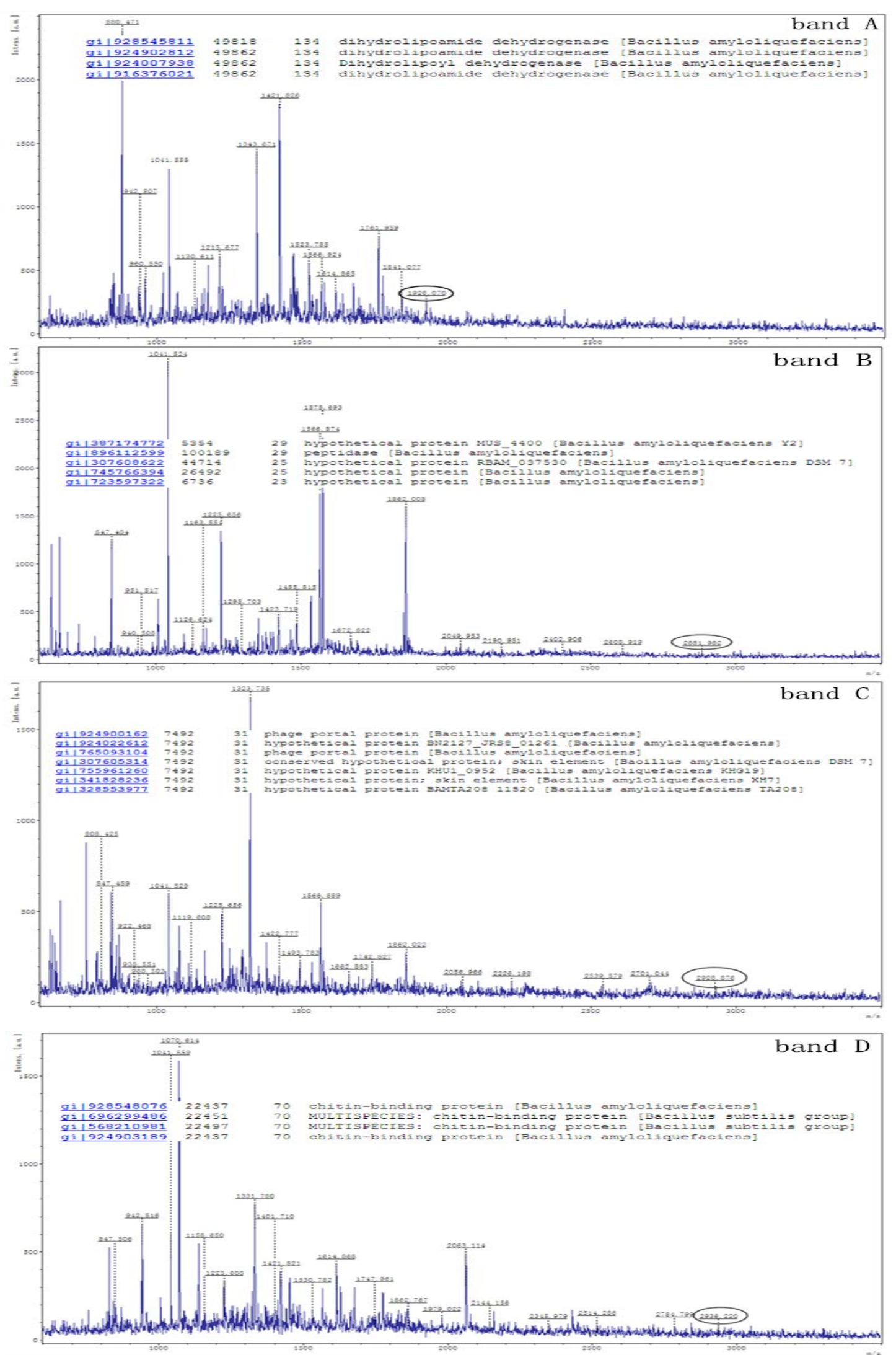

Fig. 7. The mass spectrum of extracellular antimicrobial proteins from strain CMN1308; Band A: the maximum ion peak massto-charge ratio: 1926; the related protein molecular weight: $49.8 \mathrm{kD}$, the highest matching number: 134; Band B: the maximum ion peak mass-to-charge ratio: 2881; most of the related protein was hypothetical protein, and the matching number was less than 30; Band C: the maximum ion peak mass-to-charge ratio: 2928; the related protein molecular weight: $7492 \mathrm{D}$, the matching number: 31; Band D: the maximum ion peak mass-to-charge ratio: 2936; the related protein molecular weight: $22.4 \mathrm{kD}$, the highest matching number: 70 
314

Mass spectrometry of CMN1308 extracellular antimicrobial protein

Four bands were obtained from the extracellular antibacterial protein of CMN1308 through acrylamide gel electrophoresis, and the bands showed a cut off value to perform mass spectrometry. Two bands were identified with mass spectrometry. The maximum mass-to-charge ratio of ion peak of band A was 1926. Compared with NCBI database, the related protein molecular weight $(49.8 \mathrm{kD})$ with the highest matching number (134) was found out, and analysis showed that the substance of band A was dihydrolipoamide dehydrogenase.

DLDH (dihydrolipoamide dehydrogenase) is an essential and necessary component in $3 \alpha$ pyruvate dehydrogenase complexes (Zhou et al., 2015b). DLDH is widely distributed in the mitochondria (the organs or tissues and several microorganisms of animals and plants), and also distributed in the plasma membrane of various organisms (Mcmillan et al., 2005). DLDH plays an important role in the metabolic pathway, and is also involved in the metabolism of living organisms. Thus, DLDH has been studied in the field of biopharmaceuticals. Its biological functions and effects are studied continuously (Huo et al., 2010). It was reported that DLDH is an important component of Gly degradation system, which transports lactose and maltose by protein and coenzyme $\mathrm{Q}$ (Liu et al., 2015).

Concerning the study of Bacillus spp. on the production of DLDH, it was limited only to the function of pyruvate dehydrogenase (Wu et al., 2008). Jiang et al. (1971) reported that DLDH produced from B. subtilis WY34 (a strain that produces high-yield of mannase) is an extracellular enzyme. The enzyme that was separated and identified in this study was from the fermentative supernatant of CMN1308, and is also considered as the extracellular enzyme that is produced through metabolism. Many study reports showed that DLDH acted on intracellular protein or plasma membrane in other bacteria (Liu et al., 2015). Thus, these results indicated special physiological function of DLDH by intracellular secretion.

The maximum mass-to-charge ratio of band D was 2936, and the molecular weight of the protein was $22.4 \mathrm{kDa}$. This substance was identified as chitin-binding protein [Bacillus amyloliquefaciens].

CBP (Chitin-binding protein) is a protein that binds specifically to chitin, and is widely distributed in animals, plants and microorganisms (Frederiksen et al., 2013). CBP not only binds with chitin to make its structure loose, but also strengthens the enzymatic activity to improve the degradation efficiency greatly. It not only acts as an environmentally protective agent, but also as a resource saving, which has a very high application value (Liu et al., 2011). In addition, since CBP has the capacity of binding with monosaccharide and polysaccharide substrates, the corresponding protein sterilization and antifungal activity can be produced (Aamer Mehmood et al., 2014).

The mass spectrum result of bands $\mathrm{B}$ and $\mathrm{C}$ were not in accordance with the result of Tricine-SDS-PAGE electrophoresis. Majority of the related proteins comparing with NCBI database were hypothetical proteins, and the matching number was less than 50. It was speculated that the substance of bands B and C might be two new proteins. Some issues such as property identification and antibacterial activity require further research and exploration. Thus, the antibacterial substance secreted from CMN1308 is mainly surfactin, flagellin $29.5 \mathrm{kDa}$, DLDH $49.8 \mathrm{kDa}$ and chitinbinding protein $22.4 \mathrm{kDa}$. The mechanism of how these active ingredients act on pathogenic bacteria require further research.

\section{Conclusions}

In this research, several different antimicrobial peptides have been isolated and identified from CMN1308 in intracellular and extracellular separately. The experimental results showed that the surfactin and flagellin were isolated from intracellular of CMN1308, the DLDH and chitinbinding protein was obtained from extracellular of CMN1308. It was speculated that the antibacterial substance secreted from CMN1308 is mainly surfactin, flagellin $29.5 \mathrm{kDa}, \mathrm{DLDH} 49.8$ $\mathrm{kDa}$ and chitin-binding protein $22.4 \mathrm{kDa}$. The strain CMN1308 has the potential to be developed as a commercial biological control agent for chestnut common pathogenic.

\section{Acknowledgements}

This work was supported by the Foundation for Innovative Research Group of Hubei Educational Office (T201619), Youth Foundation for Science Research of Hubei Educational Office (Q20132909); Youth Foundation for innovative research team of Huanggang Normal University (201613303).

\section{References}

Aamer Mehmood M, Hussain K, Latif F, Rizwan Tabassum M, Gull M, Shahid Gill S, Saqib A, Iqbal Z (2014). Synergistic action of the antifungal $\beta$-chitin binding protein CBP50 from Bacillus thuringiensis with bacterial chitinases. Current Proteomics 11:245-251.

Benitez LB, Velho RV (2012). Antimicrobial factor from Bacillus amyloliquefaciens inhibits Paenibacillus larvae, the causative agent of American foulbrood. Archives of Microbiology 194:177-185.

Elmer PG, Reginski T, Hill RA (2008). Biological control of plant diseases.. US, pp 1267-1271.

Frederiksen RF, Paspaliari DK, Larsen T, Storgaard BG, Larsen MH, Ingmer H, Palcic MM, Leisner JJ (2013). Bacterial chitinases and chitinbinding proteins as virulence factors. Microbiology 159:833-847.

Gómez Casado E (2015). Use of flagellins from the genus Marinobacter as vaccination adjuvants. US $9061002 \mathrm{~B} 2$.

Hermann SG (2006). Tricine-SDS-PAGE. Nature Protocols 1:16-22.

Huo J, Shi H, Yao Q, Chen H, Wang L, Chen K (2010). Cloning and purification of recombinant silkworm dihydrolipoamide dehydrogenase expressed in Escherichia coli. Protein Expression and Purification 72:95100.

Jiang Z, Wei Y, Li D, Li L, Chai P, Kusakabe I (2006). High-level production, purification and characterization of a thermostable $\beta$ mannanase from the newly isolated Bacillus subtilis WY34. Carbohydrate Polymers 66(1):88-96.

JiangLF, Qian ZG, Yang HL, ChengZ, Wang W (2007).Improvement on gel electrophoresis method for separating small molecule polypeptide. Chemical World 48:200-202. 
Juan $H$ (2014). Study on screening, identification of postharvest pathogens of chestnut and the antiseptic technique. Master, Wuhan Institute of Technology, Wuhan, China

Leelasuphakul W, Hemmanee P, Chuenchitt S (2008). Growth inhibitory properties of Bacillus subtilis strains and their metabolites against the green mold pathogen (Penicillium digitatum Sacc.) of citrus fruit. Postharvest Biology and Technology 48:113-121.

Li N, Yan C, Hua D, Zhang D (2013). Isolation, purification, and structural characterization of a novel polysaccharide from Ganoderma capense. International Journal of Biological Macromolecules 57:285-290.

Liao T, Qin J, Yuan G, Li Q, Lin W, Peng H, University G (2014). Isolation and purification of an antimicrobial substance produced by Bacillus megaterium strain B196. Plant Protection 40:16-21(in Chinese).

Liu L, Sun Z, Liu J, Shi J, Chen C, Zhang H (2015). Prokaryotic expression and analysis of Brucella IV secretion system protein BMEI1069 gene. Modern Journal of Animal Husbandry \& Veterinary Medicine 3:6-12 (in Chinese).

Liu Y, TaoJ, Yan Y,LiB, Li H,LiC (2011). Biocontrol efficiency of Bacillus subtilis SL-13 and characterization of an antifungal chitinase. Chinese Journal ofChemical Engineering 19:134-140.

Mcmillan PJ, Stimmler LM, Foth BJ, Mcfadden GI, Müller S (2005). The human malaria parasite Plasmodium falciparum possesses two distinct dihydrolipoamide dehydrogenases. Molecular Microbiology 55:27-38.

Miao EA, Andersennissen E, Warren SE, Aderem A (2007). TLR5 and Ipaf: dual sensors of bacterial flagellin in the innate immune system. Seminars in Immunopathology 29:275-288.

MoeNKT,Su MT, Suzuki K, Nakai R, Terahara T, Imada C, Kobayashi T (2015). Production of an antibacterial substance by Bacillus mojavensis strain F412 isolated from a Myanmar shrimp product fermented with boiled rice. Fisheries Science 81:1-8.

Pagoria PF, Mitchell AR, Whipple RE, Carman LM (2014). Thin-layer chromatography and colorimetric analysis of multi-component explosive mixtures. OSTIIdentifier 1151765.

Scholz R, Vater J, Budiharjo A, Wang Z, He Y, Dietel K, Schwecke T, Herfort S, Lasch P, Borriss R (2014). Amylocyclicin, a novel circular bacteriocin produced by Bacillus amyloliquefaciens FZB42. Journal of Bacteriology 196:1842-1852.
Stein T (2005). Bacillus subtilis antibiotics: structures, syntheses and specific functions. Molecular Microbiology 56:845-857.

Trefilov A, Imendoerffer M, Sekot G, Strobl F, Jungbauer A, Hahn R (2015). A microscale method of protein extraction from bacteria: Interaction of Escherichia coli with cationic microparticles. Journal of Biotechnology 207:21-29.

Villeneuve DC, Butterfield AG, Grant DL, Mccully KA (1970). The detection, separation and quantitative recovery of thirteen organophosphorus pesticides on silica gel GF254 thin-layer chromatograms. Journal of Chromatography A 48:567-571.

Wei FL, Liang YZ (2011). Study on the antimicrobial activity of flavonoids in Clausena indica (Datz) olive fruits. Medicinal Plant 9:25-29 (in Chinese).

Wu A, Jiang Z, Wei Y (2008). Purification of an extracellular dihydrolipoamide dehydrogenase from Bacillussubtilis.Journal ofChina Agricultural University 13:16-19.

YangSW (2011). Comparative study on the antibacterial activity of $32 \mathrm{kinds}$ of Chinese herbal medicine. Journal of Anhui Agricultural Sciences 39:1361-1366.

Ye YF, Li QQ, Yuan GQ, Fu G, Miao JH, Lin W (2011). Purification of antimicrobial substance produced by Bacillus subtilis B47 and its effect on southern corn leaf blight. Chinese Journal of Biological Control 27:357-361.

Zhang X, Linling LI, Cheng S, Cheng H (2016). Characterizing CMN1308, a novel strain of Bacillus amyloliquefaciens, for potential biological control application. Notulae Botanicae Horti Agrobotanici Cluj-Napoca 44:60-66.

Zhou D, Li L, Wu Y, Fan J, Ouyang J (2015a). Salicylic acid inhibits enzymatic browning of fresh-cut Chinese chestnut (Castanea mollissima) by competitively inhibiting polyphenol oxidase. Food Chemistry 171:19-24.

Zhou Y, HuoJ,Jiang TY, Xia HC, Liu HT, Yuan X, Xu RF, Chen KP, Shi HF (2015b). Subcellular localization, transcription, expression, and activity of dihydrolipoamide dehydrogenase (DLDH) during developmental stages and in different tissues of silkworm. Annals of the Entomological Society of America 108:562-567. 